\title{
Knowledge, attitudes and practice of healthcare ethics and law among doctors and nurses in Barbados Seetharaman Hariharan ${ }^{*}{ }^{\dagger}$, Ramesh Jonnalagadda ${ }^{\dagger}$, Errol Walrond ${ }^{\dagger}$ and Harley Moseley ${ }^{\dagger}$
}

Address: School of Clinical Medicine \& Research, The University of the West Indies, Queen Elizabeth Hospital, Barbados, West Indies

Email: Seetharaman Hariharan* - uwi.hariharan@gmail.com; Ramesh Jonnalagadda - rameshj@caribsurf.com; Errol Walrond - erwalrond@caribsurf.com; Harley Moseley - hslm2@caribsurf.com

* Corresponding author †Equal contributors

Published: 09 June 2006

BMC Medical Ethics 2006, 7:7 doi:10.1186/1472-6939-7-7
Received: 10 February 2006

Accepted: 09 June 2006

This article is available from: http://www.biomedcentral.com/1472-6939/7/7

(c) 2006 Hariharan et al; licensee BioMed Central Ltd.

This is an Open Access article distributed under the terms of the Creative Commons Attribution License (http://creativecommons.org/licenses/by/2.0), which permits unrestricted use, distribution, and reproduction in any medium, provided the original work is properly cited.

\begin{abstract}
Background: The aim of the study is to assess the knowledge, attitudes and practices among healthcare professionals in Barbados in relation to healthcare ethics and law in an attempt to assist in guiding their professional conduct and aid in curriculum development.
\end{abstract}

Methods: A self-administered structured questionnaire about knowledge of healthcare ethics, law and the role of an Ethics Committee in the healthcare system was devised, tested and distributed to all levels of staff at the Queen Elizabeth Hospital in Barbados (a tertiary care teaching hospital) during April and May 2003.

Results: The paper analyses 159 responses from doctors and nurses comprising junior doctors, consultants, staff nurses and sisters-in-charge. The frequency with which the respondents encountered ethical or legal problems varied widely from 'daily' to 'yearly'. $52 \%$ of senior medical staff and $20 \%$ of senior nursing staff knew little of the law pertinent to their work. $11 \%$ of the doctors did not know the contents of the Hippocratic Oath whilst a quarter of nurses did not know the Nurses Code. Nuremberg Code and Helsinki Code were known only to a few individuals. 29\% of doctors and $37 \%$ of nurses had no knowledge of an existing hospital ethics committee. Physicians had a stronger opinion than nurses regarding practice of ethics such as adherence to patients' wishes, confidentiality, paternalism, consent for procedures and treating violent/non-compliant patients $(p=0.01)$

Conclusion: The study highlights the need to identify professionals in the workforce who appear to be indifferent to ethical and legal issues, to devise means to sensitize them to these issues and appropriately training them.

\section{Background}

There has been growing public concern regarding the ethical conduct of healthcare professionals. This is often reflected as complaints about poor ethical conduct and an increasing use of litigation against healthcare practitioners.

Although ethics as applied to medical practice dates back to the ancient civilization by the symbolic adherence to 
the Hippocratic Oath, codes of conduct and laws regulating the profession are devised and updated from time to time [1]. These codes have been included in the health professionals' training curriculum in many countries, and there has been a growth in the number of ethicists and ethical committees. Despite this, complaints against healthcare professionals appear to proliferate. This may be a reflection of both an increased public awareness as well as the inappropriate practices by the healthcare professionals.

Traditional medical training offers little help in resolving the ethical dilemmas encountered by healthcare professionals. There are opinions that very few physicians trained in the Caribbean have been exposed to training in this important area of medical practice. However, on qualifying, healthcare professionals are expected to know about ethical practice during application of their skills [2].

There have been many reports stressing the importance of incorporating ethical and legal issues into medical curricula [3-5]. There is also an argument that doctors and nurses should be taught medical ethics simultaneously [6]. There are reports of unethical behavioural patterns of medical students and medical practitioners with patients as well as colleagues [7-9]. The value of both positive and negative role models in teaching medical ethics has been well recognized $[10,11]$.

There are many recommendations to strategize the teaching of medical ethics, most of it emphasizing the importance of tailoring it to the needs of the particular society in which it would be relevant. Medical ethics teaching should also be all inclusive, such as the teaching the value of 'heart' over 'mind', the value of incorporating deontological concepts etc [12].

On the other side of the spectrum, teaching medical ethics as if it is a scientific body of knowledge could also be dangerous. This is because it may miss the individualistic perception of morality and ethics innate to every professional, which would have been constructed by one's own unique cultural, socioeconomic and geographical background [13]. Hence the curriculum of medical ethics should be tailored to the social and cultural background where it is taught.

In order to formulate ethical curriculum germane to every region, the first step may be to determine the current basic knowledge and attitudes of the healthcare practitioners in the region. There have been few standard yardsticks designed to measure what is known and practised, so that educational efforts may be better targeted [14]. Physicians and nurses work closely together for patient-care, but the professional relations between the two categories may have differences with respect to their attitudes towards patient-care [15]. With this background the present study is an attempt to elucidate the knowledge, attitude and practice of the physicians and nurses in relation to healthcare ethics and law in Barbados.

\section{Methods}

A thirty item self-administered structured questionnaire about knowledge of law and ethics and the role of an ethics committee in the healthcare system was devised de novo and tested. It was made available to all levels of staff at the Queen Elizabeth Hospital in Barbados (a tertiary care teaching hospital) during April, May 2003. The questionnaire included a full range of response options, designed to identify the practitioner's knowledge, beliefs and attitudes towards patient care I relation to healthcare ethics and law. Prior to distribution of the questionnaire a pilot study was done with a select group of healthcare workers who were asked to fill out the questionnaire and return with comments and criticism. Minor changes were made to the final instrument. The questionnaire is given in the 'Appendix' section.

The initial part of the questionnaire consisted of demographics such as occupation, age, gender, the duration of work experience and the frequency of ethical or legal problems encountered in practice. The second part of the questionnaire comprised of questions regarding the importance of knowledge of ethics and law to work, the source of knowledge of ethics and law and the preference for consultation regarding an ethical or legal problem should it arise.

Questions were asked whether the respondent knew of the presence of an ethics committee in the institution. The respondent was asked if he/she knows about the role of the ethics committee and if the ethics committee satisfied its role. There were eight roles described for the ethics committee in the questionnaire and the respondents were given a choice of 'yes', 'no or 'not sure' to respond to this question (Appendix).

In the final part of the questionnaire, respondents were asked to answer questions on everyday ethical issues, if the respondent agrees or disagrees to statements concerning ethical conduct, autonomy, paternalism, confidentiality, informing patients about wrongdoing and relatives of patient condition, informed consent, treating non-compliant or violent patient, religious beliefs influencing the treatment, abortion and euthanasia. The respondents were required to answer if they agree or disagree to the statements made on these issues and the gradation of the response was provided in a Likert scale ranging from 1 to 5 (1-strongly disagree, 2-disagree, 3-not sure, 4-agree and 5 -strongly agree) (Appendix). 
Among the four hundred distributed questionnaires, 373 were returned, out of which nine questionnaires were incompletely filled and were not included for analysis. These respondents included all levels of staff in the Queen Elizabeth Hospital. The present paper analyses and compares exclusively the responses of physicians and nurses ( $\mathrm{n}=159$ ) among the survey. Data were analysed using Statistical Package for Social Sciences (SPSS) - version 8 software. Descriptive analyses were done for all data; the attitudes towards practical ethical problems were compared between nurses and physicians using a Chi square test. A Phi and Cramer's V value was obtained to determine the strength of the difference in their opinions. Statistical significance was fixed at the level of $\mathrm{p}<0.05$.

\section{Results}

A total of 159 respondents belonged to the category of either physicians or nurses. Interns, post-graduate medical residents, senior house officers and registrars were considered as junior physicians and the rest falling into the category of consultant physicians. $47 \%$ of the respondents were physicians, and 53\% were nurses including sistersin-charge.

Table 1 shows the demographics of physicians and nurses who responded to the questionnaire. There were more female nurses and more male consultant physicians consistent with the general trend.

The age distribution of the respondents was also consistent with the categories of medical and nursing staff. Work experience stretched across the entire spectrum of 1 year to over 31 years and was consistent with the occupations and ages of respondents. $90 \%$ of junior physicians were in the age group of $20-29$ years and $65 \%$ of them had $4-10$ years work experience. $72 \%$ of staff nurses were in the age group of 30-49 years and $60 \%$ of them had work experience of 7-20 years. $70 \%$ of consultant physicians and $80 \%$ of sisters-in-charge had a work experience of 20 years and more.

Figure 1 shows the responses to the frequency of ethical and legal problems encountered by the physicians and nurses. There were more physicians than nurses who encountered these problems on a daily and monthly basis and more nurses than physicians who encountered them on yearly basis. Some of the sisters-in-charge responded that they never encountered such a problem.

All the physicians and $90 \%$ of nursing staff responded that knowledge of ethics is important to their work. Only one nurse responded that knowledge of ethics was "not at all important". There was a good correlation in that those who responded that they saw ethical problems every day never responded that ethical knowledge was unimportant.

Figure 2 shows the sources of knowledge regarding medical ethics and law. More than half of the respondents answered that they acquired their knowledge of ethics and law from multiple sources. More number of nurses than physicians responded that they acquired their knowledge of ethics and law during training. More than $70 \%$ of physicians and nurses responded that they acquired their knowledge of ethics during work.

A little more than half of both physicians and nurses responded that they had "no" or 'little' knowledge of the law; $45 \%$ of sisters-in-charge said they knew most of the law pertaining to work.

Among the $11 \%$ of physicians who did not know the main contents of the Hippocratic Oath, there were 5 junior physicians, one consultant physician and one General Practitioner. Sixty percent of sisters-in-charge also responded that they knew the contents of the Hippocratic Oath. However, 34\% nurses and one sister-in-charge did not know the "Nurses Code". Over 90\% physicians and nurses did not know of the Nuremberg Code or the Helsinki Declaration.

Tables 2 and 3 show the preferences of physicians and nurses as to whom to approach when faced with an ethical and legal problem. While majority of the nurses said they would approach the matron, majority of physicians said they would approach the immediate supervisor.

$29 \%$ of physicians and $37 \%$ of nurses were unaware of the existence of an ethics committee at the institution. Of those who answered that there was a committee, many physicians felt that the committee is not fulfilling its role. $17 \%$ of physicians and $41 \%$ of nurses felt that the com-

Table I: Demographics of respondents

\begin{tabular}{ccc}
\hline Category & Number (\%) & Gender ratio (M:F) \\
\hline Junior physicians & $48(30 \%)$ & $1.2: 1$ \\
Consultant physicians & $27(17 \%)$ & $4.4: 1$ \\
Nurses & $64(40 \%)$ & $1: 15$ \\
Sisters-in-charge & $20(13 \%)$ & $0: 1$ \\
\hline
\end{tabular}


Table 2: Preference in consulting on an ethical problem

\begin{tabular}{|c|c|c|}
\hline Whom to consult & Physicians (\%) & Nurses (\%) \\
\hline Colleague & 58 & 35 \\
\hline Supervisor & 47 & 33 \\
\hline Head of Department & 49 & 51 \\
\hline Chief of Medical staff & 23 & 0 \\
\hline Matron & 0 & 40 \\
\hline Hospital Administrator & 8 & 29 \\
\hline Ethics Committee & 36 & 17 \\
\hline Professional Association & 20 & 17 \\
\hline Priest & 8 & 33 \\
\hline Text, Internet & 13 & 4 \\
\hline Close friend/family & 9 & 25 \\
\hline
\end{tabular}

mittee is performing its role satisfactorily. Among the physicians who were not aware of an ethics committee in the hospital, a quarter responded that there is a definite role for an ethics committee. Among those who were aware of an ethics committee at the hospital nearly half of physicians and nurses felt that its role is to advise the administration on ethics rules in the institution, to advice the staff and patients on ethical problems arising out of work and to teach ethical conduct. One-third of physicians and nurses felt that the role of an ethics committee is to ensure that research is conducted properly.

Table 4 depicts the responses of physicians and nurses regarding the various aspects of practicing ethics. There was a statistically significant difference between the opinions of physicians and nurses with respect to adherence to patients' wishes, confidentiality, paternalistic attitude of doctors, consent for procedures and treating violent/noncompliant patients. The doctors were stronger in their opinions than the nurses in these issues. There were no differences in the strength of the opinions regarding other issues such as informing patient regarding wrongdoing, informing close relative of a patient, seeking consent for children, abortion and euthanasia, where doctors and nurses were equally opinionated in these issues.

Table 5 shows the responses about the usefulness of the instruments to learn ethics and law. Panel discussions and workshops seemed to be useful instruments in most respondents.

\section{Discussion}

The findings of the present study clearly show the difference in the knowledge and attitudes between physicians and nurses regarding the medical ethics and law. The respondents were representative of different levels of physicians and nursing staff consisting of junior physicians inclusive of post-graduates, consultant physicians, nurses and sisters-in-charge and the responses were reflective of these categories.

The frequency of encountering the ethical and legal problems was a full spectrum ranging from "never" to "every day". Junior physicians and nurses responded that they encountered an ethical problem more often than the consultant physicians and sisters-in-charge, perhaps due to their more frequent contact with patients. The concern here is that it has to be assumed that although the junior staff had often encountered some form of ethical problem, it might not have been brought to the notice of the senior staff. Because the senior staff should act as mentors to their juniors, it is important that they should have been made aware of the problems that do arise. However it is unsure whether the juniors are perceiving problems where there are none. This may also imply that while offering training about law, ethics and the role of ethical commit-

Table 3: Preference in consulting on a legal problem

\begin{tabular}{ccc}
\hline Whom to consult & Physicians (\%) & Nurses (\%) \\
\hline Colleague & 31 & 31 \\
Supervisor & 40 & 32 \\
Chief of Medical staff & 20 & 0 \\
Matron & 0 & 39 \\
Hospital Administrator & 21 & 23 \\
Professional insurance company & 29 & 0 \\
Trade Union & 24 & 26 \\
Lawyer & 45 & 54
\end{tabular}




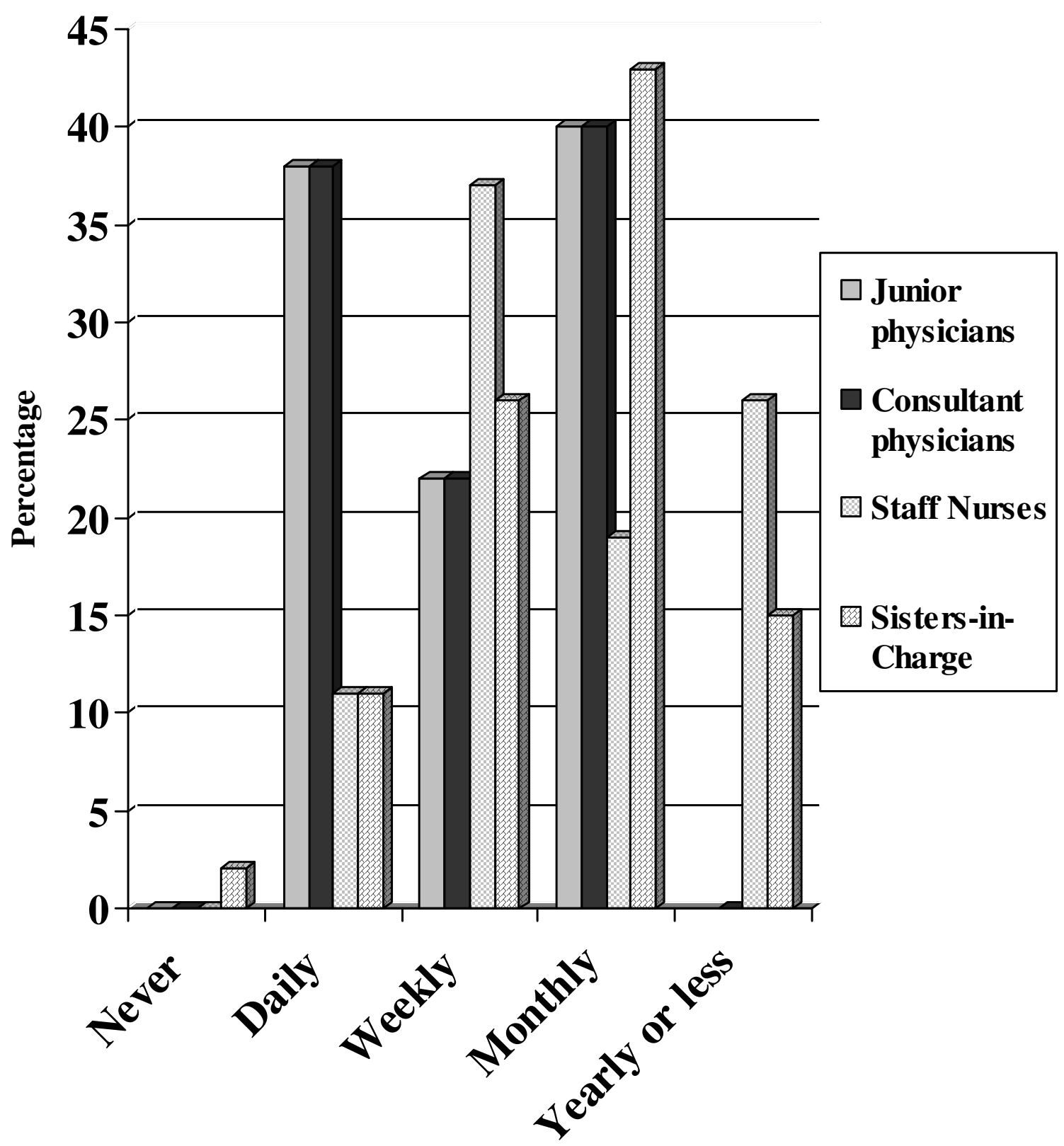

Frequency of ethical/legal problems

Figure I

Frequency of ethical or legal problems encountered.

tees, both the junior and senior staff needs to be included. If the senior staffs function autonomously during ethical dilemmas, even when they lack adequate knowledge of ethics, this may send wrong signals to the junior staff that adequate knowledge of ethics may be unnecessary for a successful practice [16]. 


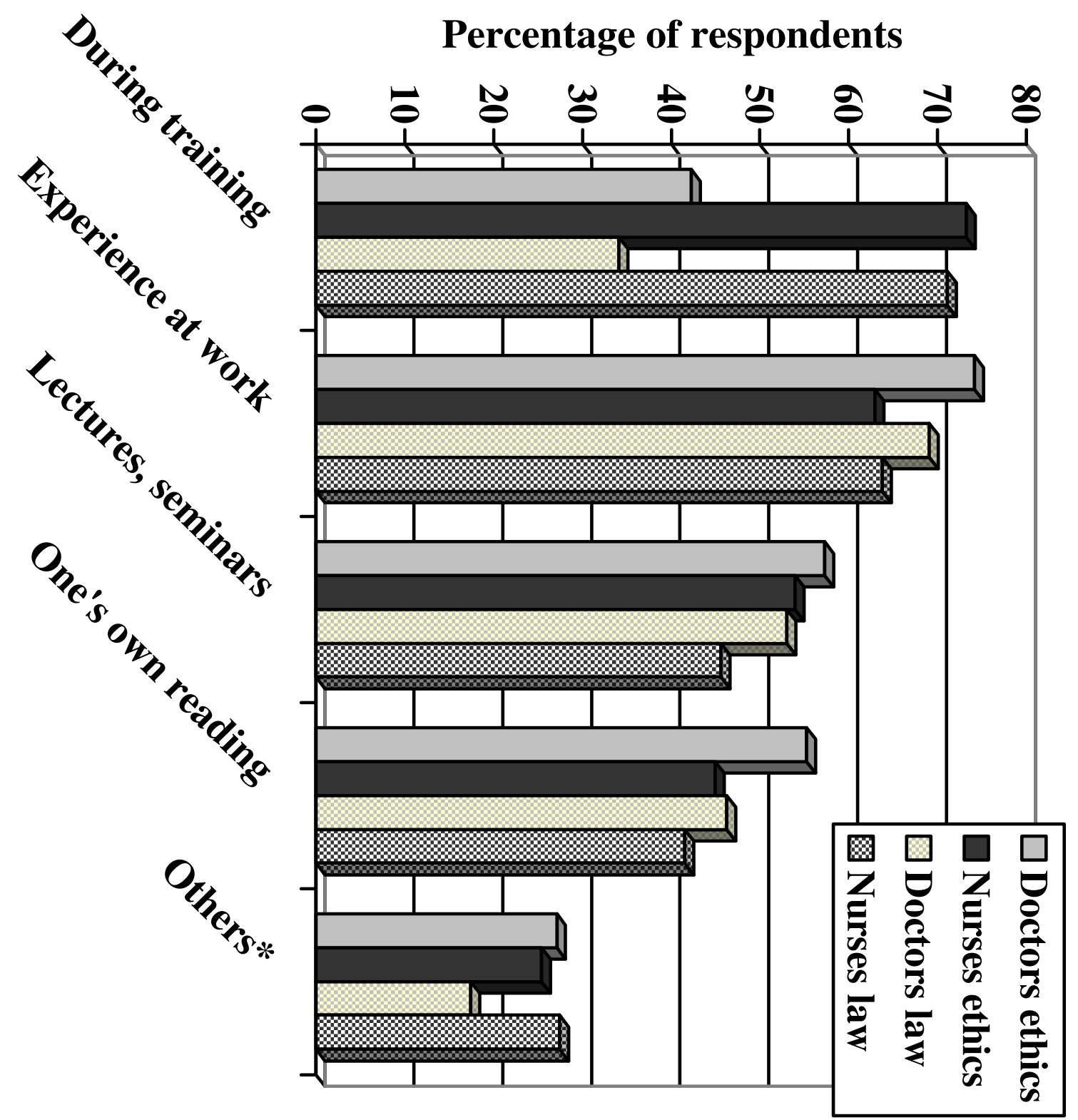

Figure 2

Source of knowledge of healthcare ethics and law. * Church, court reports etc. 
Table 5: Instruments for learning ethics and law

\begin{tabular}{lcccc}
\hline $\begin{array}{l}\text { Instruments found } \\
\text { useful }\end{array}$ & Physicians (\%) & & Nurses (\%) \\
\cline { 2 - 5 } & Juniors & Consultants & Staff nurses & Sisters-in-charge \\
\cline { 2 - 5 } & & & 43 & 45 \\
Ethics journals & 58 & 63 & 33 & 40 \\
Books on ethics & 58 & 78 & 25 & 25 \\
General texts & 60 & 80 & 29 & 33 \\
Media (Newspapers/TV) & 57 & 56 & 33 & 25 \\
Workshops & 74 & 59 & 47 & 50 \\
Lectures (UG/CME) & 58 & 59 & 43 & 30 \\
Panel discussions & 71 & 37 & 33 & 30 \\
Case conferences & 19 & & & \\
\hline
\end{tabular}

UG $=$ Undergraduate lectures

$\mathrm{CME}=$ Continuing Medical Education lectures

Most of the respondents agreed to the importance of ethical knowledge, although one-tenth of the staff nurses did not think that it is important. Those respondents, who thought that the knowledge of ethics and law was unimportant, also responded that they never saw problems. Perhaps due to the poor awareness regarding ethics and ethical situations, many of these respondents would not have possibly recognized the problems at workplace.

Very few respondents had obtained their knowledge of ethics and law from a single source. It is also interesting to note that the source of knowledge of healthcare ethics and law amongst junior physicians during training appeared to be less important than the experience at work, lectures and seminars and one's own reading (2). This shows that the curricular training regarding ethics and law pertaining to work is either inadequate or ineffective. Traditionally, healthcare personnel receive limited training in formal ethics even though their daily work involves direct and often crucial intervention in others' lives [17]. The teaching of medical ethics was introduced as a distinct entity into the medical curriculum of the Faculty of Medical Sciences, The University of the West Indies in 1991, but this teaching has been didactic in a lecture theatre setting [18].

Table 4: Practice of ethics

\begin{tabular}{|c|c|c|c|c|c|c|}
\hline Issues in practice of medical ethics & $\begin{array}{l}\text { Occupati } \\
\text { on }\end{array}$ & Disagree & Agree & $\begin{array}{l}\text { Chi } \\
\text { square }\end{array}$ & $\underset{V}{\text { Cramer's }}$ & p-value \\
\hline \multirow[t]{2}{*}{ Patient's wishes must always be adhered to } & Physicians & 43 & 23 & 4.0 & 0.15 & $P=0.03$ \\
\hline & Nurses & 65 & 26 & & & \\
\hline \multirow[t]{2}{*}{ Patient should be always informed of wrongdoing } & Physicians & 11 & 68 & 0.23 & 0.09 & $p=0.17$ \\
\hline & Nurses & 7 & 79 & & & \\
\hline \multirow[t]{2}{*}{ Confidentiality - not important } & Physicians & 82 & 1 & 11.2 & 0.26 & $p=0.001$ \\
\hline & Nurses & 76 & 14 & & & \\
\hline \multirow[t]{2}{*}{ Doctor should do best irrespective of patient's opinion } & Physicians & 67 & 10 & 8.0 & 0.22 & $p=0.004$ \\
\hline & Nurses & 61 & 28 & & & \\
\hline \multirow[t]{2}{*}{ Consent only for operations - not for tests and medications } & Physicians & 72 & 6 & 3.7 & 0.15 & $P=0.04$ \\
\hline & Nurses & 74 & 16 & & & \\
\hline \multirow[t]{2}{*}{ Close relatives should always be told about patient condition } & Physicians & 62 & 17 & 2.6 & 0.12 & $p=0.07$ \\
\hline & Nurses & 60 & 29 & & & \\
\hline \multirow[t]{2}{*}{ Children should never be treated without consent of parent } & Physicians & 13 & 70 & 0.78 & 0.07 & $P=0.25$ \\
\hline & Nurses & 10 & 80 & & & \\
\hline \multirow[t]{2}{*}{ Doctors \& nurses should refuse to treat a violent patient } & Physicians & 7I & 7 & 5.9 & 0.19 & $P=0.01$ \\
\hline & Nurses & 67 & 20 & & & \\
\hline \multirow[t]{2}{*}{ If law allows abortion, doctors cannot refuse to do abortion } & Physicians & 83 & 3 & 3.2 & 0.13 & $P=0.07$ \\
\hline & Nurses & 78 & 9 & & & \\
\hline \multirow[t]{2}{*}{ If a patient wishes to die, he or she should be assisted in doing so } & Physicians & 81 & 2 & 1.9 & 0.11 & $P=0.15$ \\
\hline & Nurses & 80 & 6 & & & \\
\hline \multirow{2}{*}{$\begin{array}{l}\text { If patients refuses treatment due to beliefs, they should be } \\
\text { instructed to find another doctor }\end{array}$} & Physicians & 66 & 11 & 1.4 & 0.09 & $P=0.17$ \\
\hline & Nurses & 77 & 7 & & & \\
\hline
\end{tabular}


It has been stressed that teaching and training which commence at the start of the course of study in medical and other healthcare professional schools, should be an ongoing process akin to continuing medical and nursing education [19]. Since both physicians and nurses feel that their main source of knowledge of healthcare ethics and law was during experience at work, such job experiences should be used to reinforce ethical knowledge and practice.

Another major finding of the study was that the majority of the respondents did not know enough of the law pertaining to their workplace. Also, there were some physicians and nurses who did not know the contents of their respective codes. The fact that more than $90 \%$ of the respondents had no knowledge regarding the Nuremberg Code and or the Helsinki Declaration indicates that there is very little knowledge regarding the ethics of research.

Many of the respondents preferred to consult either their colleague, immediate supervisor or the head of their department for ethical and legal issues. Although many of them have registered with a trade union or a professional insurance company, less than one-third only opted to consult them when faced with a legal problem at work. This is consistent with the commonly preferred opinion to settle the matter in the departmental level rather than taking it farther into higher levels. It is interesting that twothirds of physicians and one-third of nurses responded that they would consult a colleague despite the feeling that they knew little of the law. Does this reflect a separation of ethical from legal conduct in their minds or a discomfort with discussing problems with seniors? This study was not designed to answer that question. The relatively higher level of response from physicians and nurses that they would consult a lawyer on problems may reflect that the lawyers may be available as friends or relatives rather than any availability of funds for such consultation.

The unawareness regarding the ethical committee in the present study is very similar to another study regarding physicians' attitude and perceptions of a Hospital Ethics Committee from the United States, wherein a large number of professionals expressed dismay at the "invisibility" of the ethics committee [20]. Our Hospital Ethics Committee is currently not well known to many professionals and there is a need for making it aware to the staff of our hospital.

Responses from both medical and nursing practitioners to questions pertaining to practical ethics (Table 4) suggest that the majority of them were aware of the common ethical issues. The significantly stronger opinions of the doctors and the nurses in certain issues such as opinions of physicians and nurses with respect to adherence to patients' wishes, confidentiality, paternalistic attitude of doctors, consent for procedures and treating violent/noncompliant patients again may reflect the difference in the intensity of training between the two professionals.

On the question of autonomy there was wide difference of opinion among different cadres of medical and nursing staff. In another study on attitudes towards patient autonomy, UK nurses showed a greater commitment to patient autonomy than did any of the US groups, showing that there may be regional variations [21]. The fact that many senior level staff did not feel that the patient's wishes should be adhered to at all times, shows the lack of knowledge of the basic principles of medical ethics.

Ethical case conferences were helpful for many of the respondents to know about ethics. Case conferences are recent phenomena in our hospital and the proceedings of these case conferences are published and made available to all healthcare professionals.

\section{Conclusion}

Physicians and nurses commonly encounter ethical and legal issues in their workplace. However, many of these professionals are either unaware of their importance or unable to appropriately deal with these issues. Since the findings of the study identify that learning at workplace has been valuable to gain knowledge about ethics and law, there is a need to identify those who appear to be indifferent to ethical and legal issues and devise means to sensitize them to these issues in the workplace. Practical education in ethics, particularly in a multidisciplinary setting, could assist in bridging the gap in ethical approaches between nurses and physicians.

\section{Competing interests}

The author(s) declare that they have no competing interests.

\section{Authors' contributions}

SH coordinated the study, interpreted the data, statistically analysed the data and drafted the manuscript. RJ conceived of the study, and participated in its design and coordination and revised the manuscript. EW participated in the design of the study and revised the manuscript. HM participated in the design of the study and revised the manuscript.

All authors read and approved the final manuscript.

\section{Acknowledgements}

The study was funded by a grant from the Sir Arnott-Cato Foundation of Barbados 


\section{References}

I. Sauer JE Jr: Ethical problems facing the industry. Hospital and Health Services Administration 1985, 30:44-53.

2. Howitt M: Medical Ethics. Barbados Association of Medical Practitioners Bulletin 2002, I 52:5.

3. Mattick K, Bligh J: Teaching and assessing medical ethics: where are we now? J Med Ethics 2006, 32:181-I85.

4. Eckles RE, Meslin EM, Gaffney M, Helft PR: Medical ethics education: where are we? Where should we be going? A review. Acad Med 2005, 80: I |43-I I52.

5. Roff S, Preece P: Helping medical students to find their moral compasses: ethics teaching for second and third year undergraduates. J Med Ethics 2004, 30:487-489.

6. Hanson S: Teaching health care ethics: why we should teach nursing and medical students together. Nurs Ethics 2005, I 2:167-I76.

7. Green MJ, Farber NJ, Ubel PA, Mauger DT, Aboff BM, Sosman JM, Arnold RM: Lying to each other: when internal medicine residents use deception with their colleagues. Arch Intern Med 2000, 160:2317-2323.

8. Baldwin DC Jr, Daugherty SR, Rowley BD, Schwarz MD: Cheating in medical school: a survey of second year students at $3 \mathbf{I}$ schools. Acad Med 1996, 71:267-273.

9. Baldwin DC Jr, Daugherty SR, Rowley BD: Unethical and unprofessional conduct observed by residents during their first year of training. Acad Med 1998, 73: I 195-1200.

10. Cooper RA, Tauber Al: Viewpoint: New physicians for a new century. Acad Med 2005, 80:1086-1088.

II. Wolf $\mathrm{G}$ : Portrayal of negative qualities in a doctor as a potential teaching tool in medical ethics and humanism: Journey to the End of Night by Louis-Ferdinand Celine. Postgrad Med J 2006, 82:154-156.

12. Coulehan J: Viewpoint: today's professionalism: engaging the mind but not the heart. Acad Med 2005, 80:892-898.

13. Cowley C: The dangers of medical ethics. J Med Ethics 2005, 3 I:739-742.

14. Hicks LK, Lin Y, Robertson DW, Robinson DL, Woodrow SI: Understanding the clinical dilemmas that shape medical students' ethical development: questionnaire survey and focus group study. BMJ 200I, 322:709-7I0.

I5. Ruth E, John Price J, Williams G: Differences in ethical attitudes between registered nurses and medical students. Nurs Ethics 2003, I0:149-164.

16. Seedhouse D: Ethics: The heart of health care. New York, NY: John Wiley \& Sons; 1988.

17. Aarons DE: Issues in Bioethics. West Indian Med J 2002, 5 I:59-63.

18. Aarons DE: Issues in Bioethics. West Indian Med J 2003, 52:145-150.

19. Sulmasy DP, Dwyer M, Marx E: Knowledge, Confidence, and Attitudes Regarding Medical Ethics: How do Faculty and House Staff Compare? Acad Med 1995, 70:1038-1040.

20. Hern GH Jr: Ethics and human values committee survey: (AMI Denver Hospitals: Saint Luke's, Presbyterian Denver, Presbyterian Aurora: Summer 1989). A study of physician attitudes and perceptions of a hospital ethics committee. HEC Forum 1990, 2:105-125.

21. Dickenson DL: Practitioners' Attitudes towards Ethical Issues at the End of Life: Is the UK Actually More AutonomyMinded than the US? J Palliat Care 1999, 1 5:57-63.

\section{Pre-publication history}

The pre-publication history for this paper can be accessed here:

http://www.biomedcentral.com/1472-6939/7/7/prepub
Publish with Biomed Central and every scientist can read your work free of charge

"BioMed Central will be the most significant development for disseminating the results of biomedical research in our lifetime. "

Sir Paul Nurse, Cancer Research UK

Your research papers will be:

- available free of charge to the entire biomedical community

- peer reviewed and published immediately upon acceptance

- cited in PubMed and archived on PubMed Central

- yours - you keep the copyright

Submit your manuscript here:

http://www.biomedcentral.com/info/publishing_adv.asp
BioMedcentral 